\title{
Prechamber optimal selection for a two stage turbulent jet ignition type combustion system in CNG-fuelled engine
}

Searching for further reduction of fuel consumption simultaneously with the reduction of toxic compounds emission new systems for lean-mixture combustion for SI engines are being discussed by many manufacturers. Within the European GasOn-Project (Gas Only Internal Combustion Engines) the two-stage combustion and Turbulent Jet Ignition concept for CNG-fuelled high speed engine has been proposed and thoroughly investigated where the reduction of gas consumption and increasing of engine efficiency together with the reduction of emission, especially $\mathrm{CO}_{2}$ was expected. In the investigated cases the lean-burn combustion process was conducted with selection of the most effective pre-combustion chamber. The experimental investigations have been performed on single-cylinder AVL5804 research engine, which has been modified to SI and CNG fuelling. For the analysis of the thermodynamic, operational and emission indexes very advanced equipment has been applied. Based on the measuring results achieved for different pre-chamber configurations the extended methodology of polioptimization by pre-chamber selection and the shape of main chamber in the piston crown for proposed combustion system has been described and discussed. The results of the three versions of the optimization methods have been comparatively summarized in conclusions.

Key words: gas engine, prechamber, thermodynamic analysis, combustion, exhaust emission, optimisation

\section{Introduction}

The global production of automotive vehicles continues to increase every year, reaching the level of over 97 million units produced in 2017 [28]. Currently, the majority of these vehicles (estimated in 2012 at $96 \%$ ) are powered by combustion engines running on liquid petroleum fuels [8]. However, the availability of such fuels is increasingly limited due to the depletion of oil resources. At the same time, the content of heavier hydrocarbon fractions creates numerous problems with the emission of harmful compounds and particulate matter.

In this context, increasingly attention is paid to gaseous fuels. Among them, the most popular is natural gas, whose global production in 2017 reached over 3700 billion $\mathrm{m}^{3}$ [2]. The share of this fuel in the global energy consumption by the transport sector is forecast to increase from 3\% in 2012 to $11 \%$ in $2040[22,26]$. This is supported, inter alia, by the intensive development of CNG refueling infrastructure [5, 10] and the lower impact of pollutant emissions from gas engines on the natural environment.

Due to the relatively low density of natural gas $(0.7-0.9$ $\left.\mathrm{kg} / \mathrm{m}^{3}\right)$ [11], the lower flame propagation rate $(0.37 \mathrm{~m} / \mathrm{s}$ at $\lambda=0.9$ ) [18] and high $\mathrm{A} / \mathrm{F}$ value (17.2) [11], changing the fuel supplied to a high-speed SI engine with indirect injection from liquid to $\mathrm{CNG}$ results in a reduction of power and torque [29]. A positive aspect of using CNG in these types of constructions is the reduction of some exhaust components emission [7, 19], in particular $\mathrm{CO}_{2}$ emissions.

The parameters of natural gas listed above require the use of a dedicated system for the charge preparation and combustion. Currently, in addition to the aforementioned conventional combustion system with SI and indirect injection, two alternative system types that effectively burn natural gas can be distinguished. First is the direct injection of natural gas into the combustion chamber, which allows limiting the volumetric losses in the low engine speed range. The use of direct injection results in increased power and torque, as well as an increase in thermal efficiency [6].

An alternative solution is a two-stage combustion system (TJI - Turbulent Jet Ignition) [22, 25] that uses an ignition chamber directly powered with gas and the main chamber with external mixture preparation. There is a spark plug located in the prechamber (ignition chamber) and a gas supply channel through a one-way valve as well. This enables obtaining a rich, easily flammable gas/air mixture. The streams of burning fuel flowing through the inter-chamber channels lead to surface ignition of a lean fuel mixture located in the main combustion chamber, while the lean fuel mixture itself is prepared in a mixer or by means of gas injection into the intake manifold.

\section{Literature study}

The combustion with excess oxygen, called lean combustion, is being used due to the increase in engine thermal efficiency and to exploit the potential to reduce some engine emissions [25], with special focus put on the $\mathrm{NO}_{\mathrm{x}}$-emissions, which decreases with the increase in air-fuel equivalence ratio - in parallel with the decrease in combustion temperature - one of main factors influencing emission of these compounds. However, the biggest benefits in the reduction of thermal $\mathrm{NO}_{\mathrm{x}}$ emissions happen for the $\lambda>1.4$. This value is the lean combustion limit for conventional spark ignition systems, but can be further extended with the implementation of turbulent jet ignition (TJI), which can deliver much higher activation energy to start the combustion process of a lean mixture. Such a system can be used either without injection to the ignition chamber (passive or unscavenged configuration) or with 
prechamber injection (active or scavenged configuration) $[2,3,12]$. Hence the active TJI has been introduced to the engine, stable operation has been achieved for $\lambda \sim 2.2$, in parallel with better indicated net thermal efficiency values from $\lambda>1.2$ and also $2 \%$ greater $\eta_{\mathrm{t} \_ \text {max }}($ at $\lambda \sim 1.6)$.

The prechamber system has been widely investigated in heavy duty engines $[14,17,24]$ and the positive impact of TJI implementation has been confirmed regarding the combustion indicators. However, the high level of its complexity results in reduced scalability and confirms the necessity of functional analysis in case of small reciprocating engines [21].

TJI indicates the potential in knock characteristic improvement at high load engine operation [1]. In the scope of the mentioned study several fuel blends with reduced octane number in the range of 93-60 have been supplied during WOT operation to the dual stage combustion system in unscavenged configuration. At the constant engine speed of $1500 \mathrm{rpm}$, the knock limit extension that was sourced in improved burn rate, allowed using fuel with octane number 10 points lower. Further, with optimized ignition timing and due to the reduced ignition delay and faster combustion, the benefit of 15 octane number fuel has been proven, which enables increasing the CR by approximately 3 points and also thermal efficiency benefits [30].

The prechamber-initiated combustion system has been investigated by the authors of this study [15] with focus on determination of possible and beneficial fuel supply strategies for both chambers. The main chamber has been fed indirectly with CNG doses in the range $\mathrm{q}_{0 \_\mathrm{MC}}=(14.8-19.0)$ $\mathrm{mg} / \mathrm{inj}$, while the prechamber injection has been set at $\mathrm{q}_{0} \mathrm{PC}=$ $=(0.63-2.76) \mathrm{mg} / \mathrm{inj}$. Considering the ignitability limit for the prechamber system supplied with the main CNG dose greater than $17.7 \mathrm{mg} / \mathrm{inj}$, the top end limitation in prechamber fuel supply is clearly marked with rapid increase in CoV(IMEP) - for $\mathrm{q}_{0 \_P C}>1.7 \mathrm{mg} / \mathrm{inj}$ and a reduced HRR. As indicated, this is caused by the conditions in the precombustion chamber being too rich. In case of the low dose value $\left(\mathrm{q}_{0 \_\mathrm{MC}}=14.8 \mathrm{mg} / \mathrm{inj}\right)$, the combustion stability penalty has been observed for a much greater prechamber dose $\left(\mathrm{q}_{0 \_\mathrm{PC}}>2.2 \mathrm{mg} / \mathrm{inj}\right)$, however the prechamber supplied with fuel quantity reduced below $\mathrm{q}_{0 \_\mathrm{PC}}<1.1 \mathrm{mg} / \mathrm{inj}$ resulted in significant increase in the combustion non-uniformity. This confirms the lower ignitability limit, which is marked by too lean prechamber conditions.

Geometrical configuration of the prechamber system has a significant impact on the main combustion process. The literature-indicated prechamber cavity $\mathrm{V}_{\mathrm{pc}}$ share in total combustion chamber volume is given by [27]:

$$
r_{\mathrm{v}}=\frac{\mathrm{v}_{\mathrm{pc}}}{\mathrm{v}_{\mathrm{pc}}+\mathrm{v}_{\mathrm{mc}}}
$$

where $\mathrm{V}_{\mathrm{mc}}$ is the volume of main chamber, and varies in range of $r_{v}=(1.1-37) \%$.

Oversizing the pre-combustion cavity causes excessive energy to be transferred to the main combustion chamber (assuming a constant prechamber stoichiometry). In studies of lean mixtures combustion in the main chamber a significant increase in $r_{v}$, at a constant lambda value, results in an increase of $\mathrm{NO}_{\mathrm{x}}$ emission [13]. Other studies confirm the $5 \%$ volume limit regarding the heat losses level in various cited works of Attard, compare with [1-3].
Bunce et al. conducted research into the number of nozzles and their diameter using an optically accessible engine with a displacement of $0.601 \mathrm{dm}^{3}$ [4]. As an obvious result of increasing the number of nozzles from 4 and 8 (both with a diameter of $1.36 \mathrm{~mm}$ ) was the lower peak PC/MC pressure difference - from 6 bars at $\lambda=1.55$ to 4 bars at $\lambda=$ $=1.99$ respectively. However, the prechamber light-off accelerates with the increase in nozzle flow area. The reasons for this outcome are the better scavenging of residuals from the previous combustion cycle and more favourable air-fuel stoichiometry in the area of the spark plug. The faster prechamber light-off has its reflection in the earlier ignition of the main charge - up to $2.5 \mathrm{deg} \mathrm{CA}$ at $\lambda=1.8-$ and faster MFB10-90 promoting better control of the main combustion process. Another numerical study focused on the diameter of a single nozzle (diameters of 3, 4, 6 and $9 \mathrm{~mm}$ have been compared) and the mentioned relation has been confirmed with indication of bigger heated volume of the main chamber at the defined time instance after prechamber ignition [9].

The common impact of both the prechamber volume and the nozzles diameter on combustion stability and emission of $\mathrm{NO}_{\mathrm{x}}$ has been investigated by Shah et al. [20]. The $\mathrm{r}_{\mathrm{v}}=(1.4-3.7) \%$ and nozzle area to volume ratio $\mathrm{A}_{\mathrm{PC}} / \mathrm{V}_{\mathrm{PC}}=$ $=(0.025-0.045) \mathrm{cm}^{-1}$ have been investigated. Increasing the prechamber volume increases combustion stability, however also results in higher $\mathrm{NO}_{\mathrm{x}}$ emission. The opposite result has been noted with the increase in nozzles diameter, so both these relations need to be considered regarding the criteria, which have to be met when TJI is being applied.

As described, the impacts of system constructional features on the engine operation have been individually investigated, but there are no studies considering the prechambers multiparametrically (volume of prechamber in combination with nozzles diameter and their angularity) and providing their comparison under selected criteria. Thus, the comparative investigations have been undertaken and a new optimization method has been created, described and implemented.

\section{The objective of the research}

The decision to perform this research was to select the combustion system parameters, allowing for improvement of the engine operating indicators. The focus was on the issue of increasing the engine work cycle efficiency while minimizing the toxic exhaust emissions. For the assumptions made as stated, variables were defined as the geometrical parameters of: the prechamber and chambers in the piston, as well as the fuel supply system. The final result of the research was to find the best possible solution for the defined criterion function including indicated efficiency, $\mathrm{CO}, \mathrm{THC}$ and $\mathrm{NO}_{\mathrm{x}}$ emission intensities and the mean effective pressure value.

\section{Research methodology}

\subsection{Research objects: prechambers}

The research involved using six ignition chambers of different geometry, with parameters as shown in Table 1. Each of them has six to seventeen outflow channels with diameters ranging from 0.9 to $2.0 \mathrm{~mm}$, located in the lower part of the chamber (Fig. 1). 
Table 1. Prechambers parameters

\begin{tabular}{|c|c|c|c|c|}
\hline No. & $\mathrm{V}_{\text {chr }}$ & $\begin{array}{c}\text { No. of } \\
\text { nozzles }\end{array}$ & $\varnothing$ nozzle & Type of nozzles \\
\hline- & $\mathrm{cm}^{3}$ & - & $\mathrm{mm}$ & - \\
\hline P1 & 1.826 & 7 & 1.5 & radial (R) \\
\hline P2 & 1.826 & 6 & 1.5 & radial (R) \\
\hline P3 & 2.287 & 6 & 2.0 & radial (R) \\
\hline P4 & 2.287 & 6 & 1.5 & radial (R) \\
\hline H1 & 1.826 & $7 \mathrm{R}+3 \mathrm{~A}$ & $1.5 \mathrm{R}+1.4 \mathrm{~A}$ & radial (R)/axial (A) \\
\hline H2 & 1.826 & $12 \mathrm{R}+5 \mathrm{~A}$ & 0.9 & radial (R)/axial (A) \\
\hline
\end{tabular}

The volume of the ignition chambers was 1.8 and 2.2 $\mathrm{cm}^{3}$, constituting from $5 \%$ to $6.2 \%$ of the total volume of the combustion chamber. a)

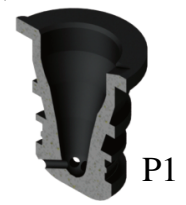

b)

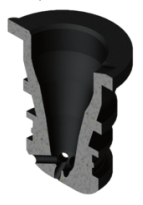

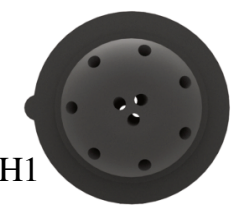

Fig. 1. Prechambers cross-section and a bottom-side image: a) P1, b) H1

Due to the location of the outflow channels and the resulting need to use different shapes of the piston crown, the chambers were divided into two groups marked with the symbols "P" and "H". The "P" chambers have radial outflow channels (R-radial), in which a piston with an "omega" combustion chamber was used (Fig. 2a). The "H" chambers were characterized by radial and axial outflow channels (H-horizontal). Placing the outflow channels in the central part of the bottom of the chamber required the use of a piston with a semicircular, open, hemi-spherical combustion chamber (Fig. 2b). a)

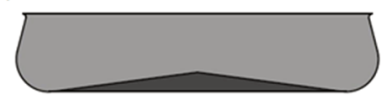

b)

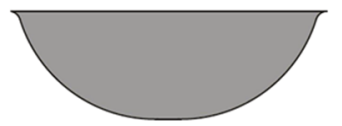

Fig. 2. Cross-section of combustion chambers used in the piston: a) omega, b) hemi-spherical

\subsection{Test-bench}

The investigations of new combustion systems have been conducted on single cylinder research engine AVL

a)

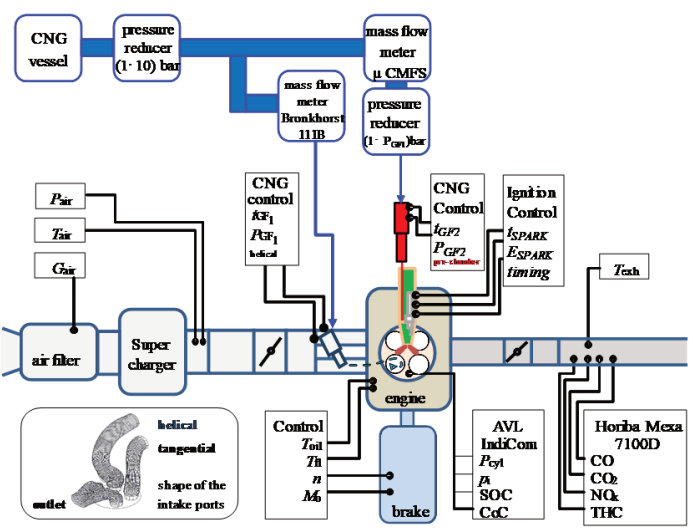

5804, originally CI, modified to use CNG fuel and with a two-stage SI combustion system (Fig. 3). Selected measuring equipment has been installed on the test rig (compare with chapter 4.3), as well as a dedicated control system.

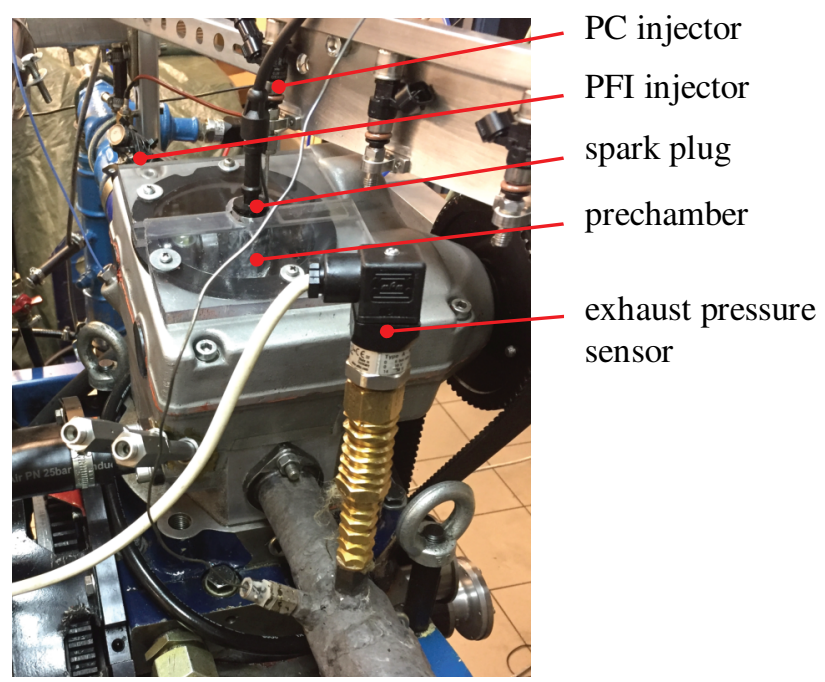

Fig. 3. AVL 5804 test bench

Fuel supply system in the first version consists of electromagnetic Bosch CNG nozzle injecting the fuel to the helical intake port - chosen based on the results of other investigations with spray ignition [16] - and the second nozzle directed into the prechamber (Fig. 4a), scavenged prechamber system has been investigated. Second version, used to achieve a better homogenization of the main mixture, consisted of a CNG mixing device, which has been installed at a greater distance from the cylinder head (Fig. $4 b)$. This change in the fuel supply system has been implemented in parallel with the introduction of a Hemi-like main combustion chamber and the use of prechambers with axial nozzles - designated as " $\mathrm{H}$ ".

The parameters of AVL 5804-engine are listed in Table 2. Auxiliary supercharging system with intake throttle has been used to achieve the required air mass flow. The exhaust system throttle body has been installed to implement the flow restriction resulting from the turbocharging system, with assumption of characteristic intake pressure $\mathrm{p}_{1}$ and exhaust pressure $\mathrm{p}_{2}$ ratio as in the full engine investigations [23]:

b)

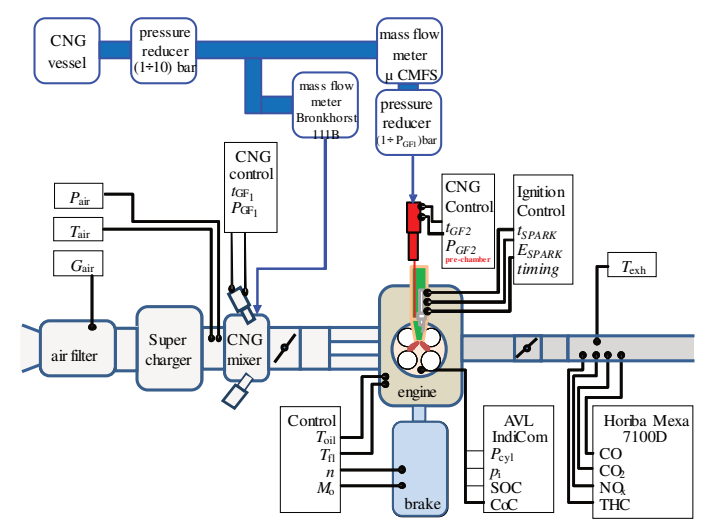

Fig. 4. Functional schematic of the test bench with AVL 5804 engine: a) prechamber injection and port fuel injection, b) prechamber injection and CNG mixer in the intake port 


$$
\mathrm{x}_{\mathrm{p}}=\frac{\mathrm{p}_{2}}{\mathrm{p}_{1}}
$$

The emissions measurements have been performed using Horiba Mexa 7100D system.

Table 2. Technical parameters of AVL 5804-engine

\begin{tabular}{|l|c|c|}
\hline Parameter & Unit & Value/Type \\
\hline Engine & - & 1-cylinder, prechamber \\
\hline Swept volume & $\mathrm{dm}^{3}$ & 0.5107 \\
\hline Bore $\times$ Stroke & $\mathrm{mm}$ & $85 \times 90$ \\
\hline Compression ratio & - & 15.2 \\
\hline Fuel supply & - & $\begin{array}{l}\text { 1. PFI (helical port), } \\
\text { prechamber injection } \\
\text { 2. Heinzmann-mixer, } \\
\text { prechamber injection }\end{array}$ \\
\hline Intake system & - & $\begin{array}{c}\text { Throttled, with auxiliary } \\
\text { supercharging system }\end{array}$ \\
\hline Exhaust system & - & Throttled \\
\hline
\end{tabular}

\subsection{Measuring equipment}

In order to precisely determine the basic parameters of the engine's operation, including the mass consumption of air and fuel, a number of indicators, engine load, as well as harmful exhaust emissions, measuring apparatus described in Table 3 was used. A fuel supply double system (indirect to the main chamber and direct to the prechamber) necessitated the use of two natural gas flowmeters with different measurement ranges. Pressure sensors installed independently in the main combustion chamber and in the prechamber allowed to determine differences in the thermodynamic processes characteristic.

Table 3. Measuring equipment of the researched engine AVL 5804

\begin{tabular}{|c|c|c|}
\hline Parameter & Description & Range \\
\hline Engine brake & $\begin{array}{l}\text { AVL AMK DW13- } \\
170\end{array}$ & $-50-300 \mathrm{Nm}$ \\
\hline Air consumption & Sensycon Sensyflow & $0-720 \mathrm{~kg} / \mathrm{h}$ \\
\hline Charging system & Eaton M62 & $0-2$ bar \\
\hline $\begin{array}{l}\text { Fuel consumption } \\
\text { (prechamber) }\end{array}$ & Bronkhorst 111B & $0.1-100 \mathrm{~g} / \mathrm{h}$ \\
\hline $\begin{array}{l}\text { Fuel consumption } \\
\text { (main chamber) }\end{array}$ & Emerson $\mu \mathrm{CMFS}$ & $0.1-2 \mathrm{~kg} / \mathrm{h}$ \\
\hline $\begin{array}{l}\text { Air pressure, fuel } \\
\text { pressure }\end{array}$ & Wika A-10 & $0-10$ bar \\
\hline $\begin{array}{l}\text { Air temperature, fuel } \\
\text { temperature }\end{array}$ & Linuatherm Pt100 & $-50-500$ deg. C \\
\hline Lubrication system & AVL 577 & $0-150^{\circ} \mathrm{C}$ \\
\hline Cooling system & AVL 577 & $0-150^{\circ} \mathrm{C}$ \\
\hline \multirow[t]{2}{*}{ Data acquisition } & AVL IndiSmart & $\begin{array}{l}\text { 8-kanałowy } \\
\text { system }\end{array}$ \\
\hline & AVL Concerto & Post-processing \\
\hline Emission measurement & Horiba Mexa 7100D & $\begin{array}{c}10-50000 \mathrm{ppmHC} \\
50-5000 \mathrm{ppm} \\
\mathrm{CO}(\mathrm{L}) \\
0,5-10 \% \mathrm{CO}(\mathrm{H}) \\
0,5-20 \% \mathrm{CO}_{2} \\
10-10000 \mathrm{ppm} \\
\mathrm{NO}_{\mathrm{x}}\end{array}$ \\
\hline
\end{tabular}


based on the real resulting lambda value - meaning not exactly for values selected as representative ones (Fig. 6). To get the emission, efficiency and IMEP values for the preselected level of lambda an interpolation procedure has been applied.

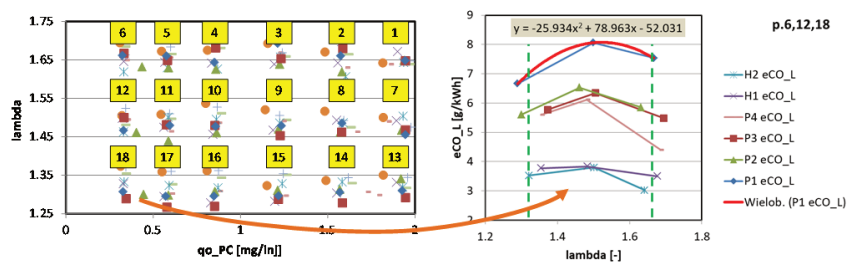

Fig. 6. The method of determining constant values of the excess air coefficient

Using the interpolation of the $a x^{2}+b x+c$ quadratic function for each CO_L emission curve based on measured values, the resulting emissions for selected lambda values (1.65, $1.5,1.32)$ were determined. Values of lambda were determined using the Van der Mond matrix (a, b, c-values). Emission $\left(\mathrm{CO}, \mathrm{THC}, \mathrm{NO}_{\mathrm{x}}\right.$ ), efficiency (eta_o) and others (IMEP, CoV_IMEP) were determined for lambda $=1.65 ; 1.5 ; 1.32$ as well (Fig. 7).

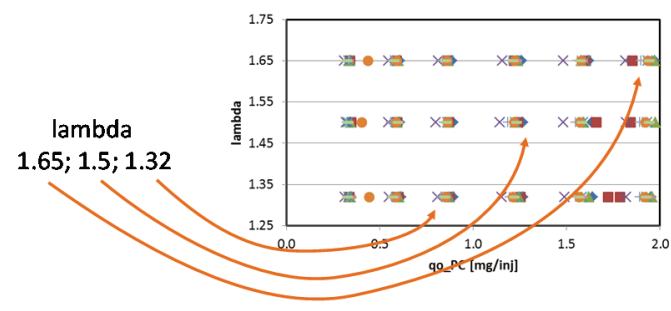

Fig. 7. Predefined constant values of excess air coefficient

By averaging of the qo_PC values, the representative points qo_PC were selected. These were: $0.35 ; 0.6 ; 0.9 ; 1.2$; 1.6; $1.9 \mathrm{mg} /$ inj (Fig. 8).

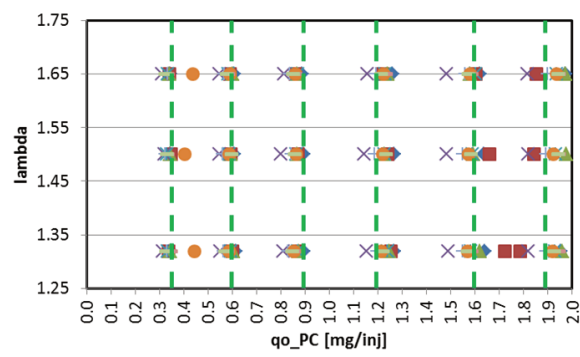

Fig. 8. Adoption of fixed fuel dose values qo_PC

Due to the lack of monotonous function for designation of qo_PC (Fig. 9) the following steps were performed:

a) for lambda values: min (1.35) and max (1.9) an extrapolation based on three curve extreme points using the Van der Mond matrix were accepted (Fig. 10);

b) for internal value points the calculation was based on interpolation (Fig. 11a) between determined measuring points (as illustrated in Fig. 11b).

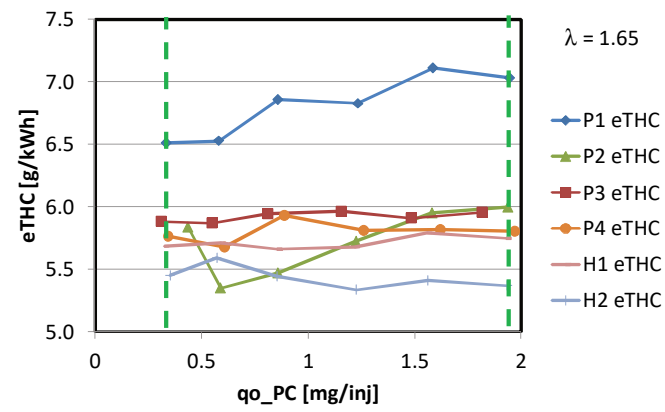

Fig. 9. Determination of the interpolated values of emission intensity (e.g. for $\mathrm{THC}$

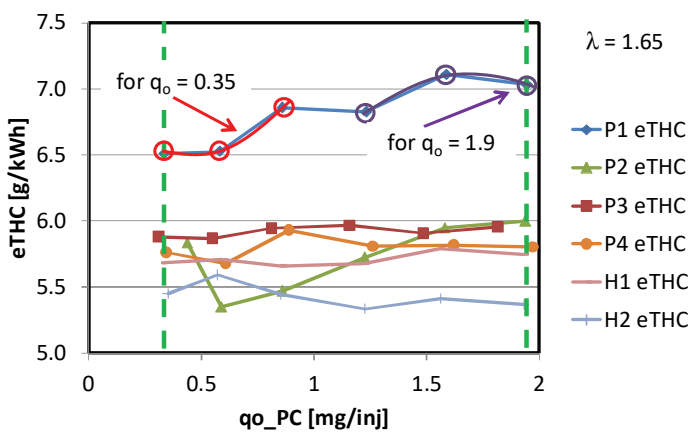

Fig. 10. Selection of points for emission intensity determination by extreme fuel doses qo_PC

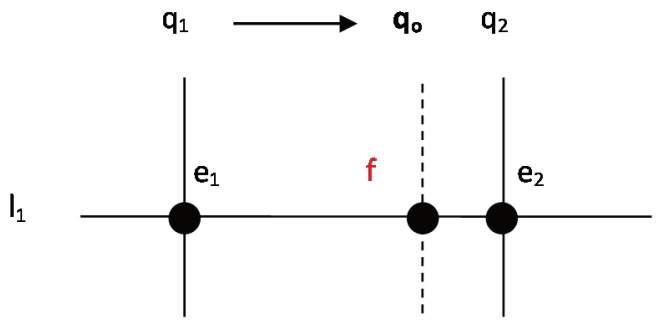

$$
\frac{f-e_{1}}{e_{2}-e_{1}}=\frac{q_{o}-q_{1}}{q_{2}-q_{1}} \quad f=e_{1}+\frac{\left(q_{0}-q_{1}\right)\left(e_{2}-e_{1}\right)}{q_{2}-q_{1}}
$$

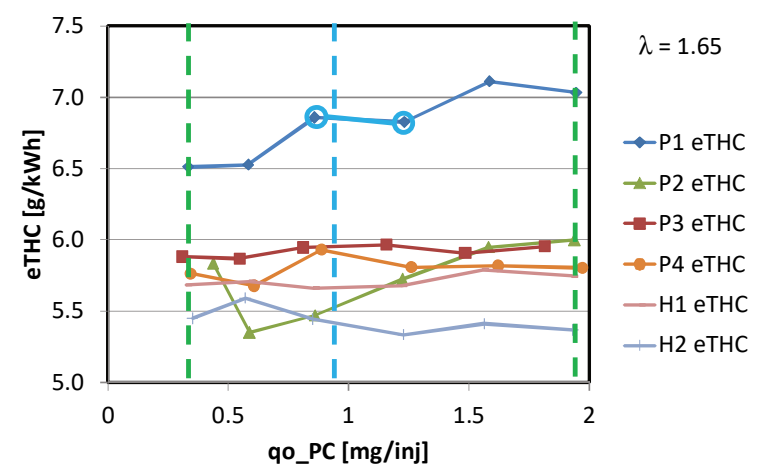

Fig. 11. Determination of emission values for internal fuel dose points qo_PC intervals: a) example of linear interpolation, b) example analysis points

For the extrapolated and interpolated data the optimization procedure described in chapter 8 was performed (Fig. 12). 


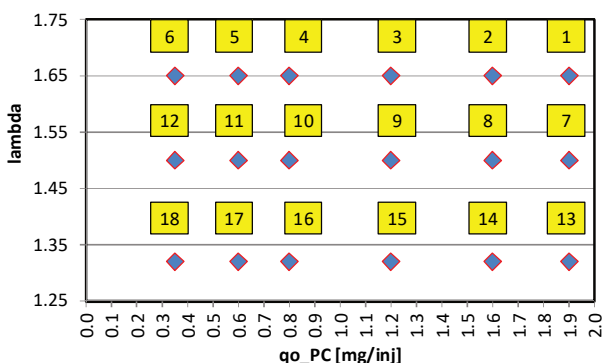

Fig. 12. The research points table after measured value normalization

\section{Analysis of thermodynamical results}

The results of the thermodynamic analysis of the engine's operating cycles indicated that the best results, mainly the highest values of the indicated mean effective pressure (IMEP), were achieved for the engine operation using the H-type prechamber ( $\mathrm{PC}$ with a double row of outflow channels). The maps shown in Fig. 13 indicate higher IMEP values for such a combustion system in the whole range compared to the values achieved using the P-type system (with a single row of outflow channels). The combustion system using prechambers with a single row of outflow channels is characterized by reaching the maximum values of IMEP in the range of smaller doses of fuel supplied to the PC. The combustion system with H-prechambers is characterized by an even increase of IMEP with the increase of the excess air coefficient. The largest recorded IMEP values were obtained for the $\mathrm{H} 2$ prechamber.

a)
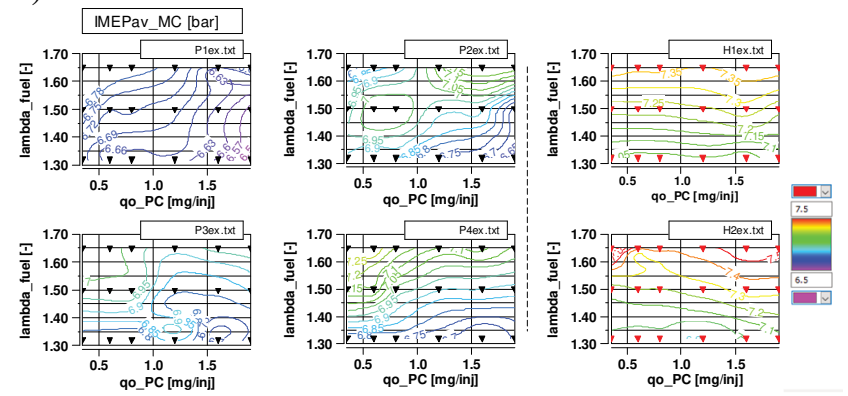

b)
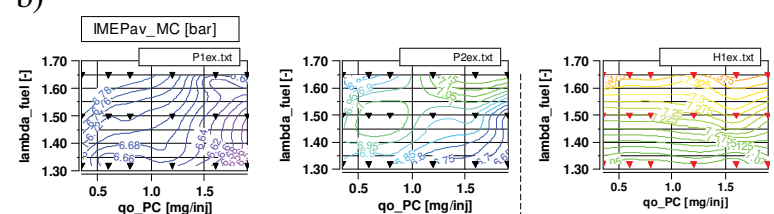

$0.5 \underset{\text { qo_PC }[\mathrm{mg} / \mathrm{in}]}{1.5}$
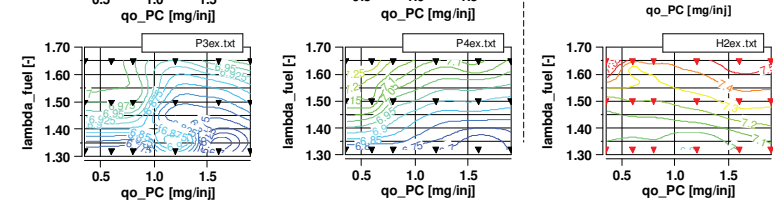

Fig. 13. The maps of IMEP-values measured for prechambers of type $\mathrm{P}(\mathrm{a})$ and type $\mathrm{H}(\mathrm{b})$

The maps of overall engine efficiency (Fig. 14) have been determined similarly to those shown above. The lowest efficiency was found for the P1 prechamber, using which the test engine achieves a maximum efficiency of 0.33 . The use of the $\mathrm{H} 1$ prechamber allowed to achieve an increase in the general engine efficiency of over $7 \%$. Similarly to the value of IMEP, the efficiency analysis also indicates an even increase of the eta_o value based on the increasing lambda value in the case of using the H-type prechamber. PCs with single outflow channels are characterized by greater sensitivity to variable prechamber fuel dosing conditions.

a)

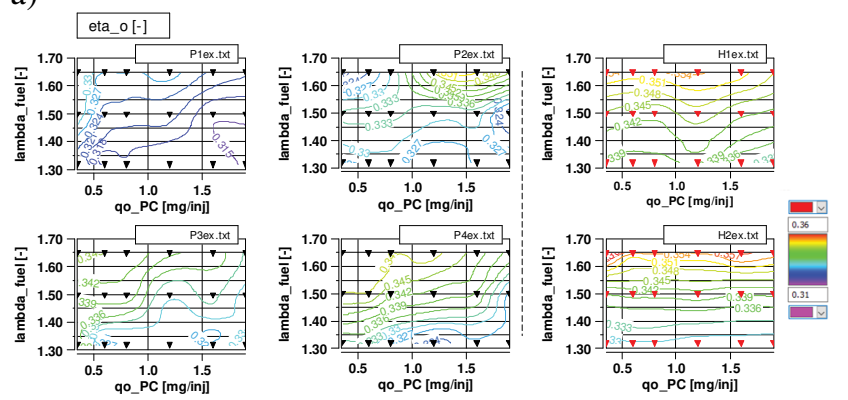

b)
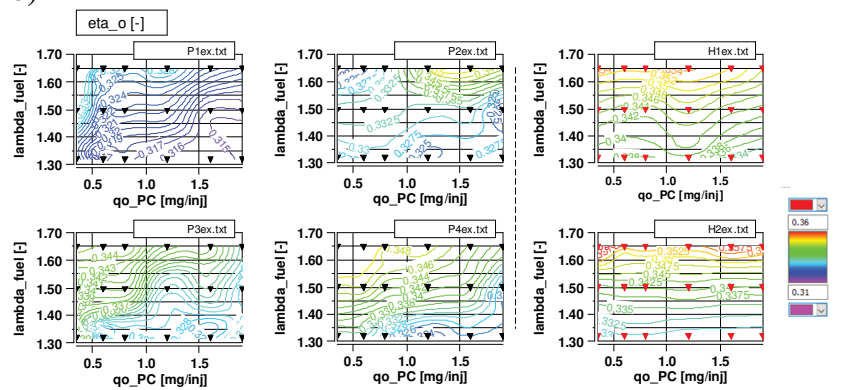

Fig. 14. The maps of overall efficiency achieved for prechamber type P (a) and type $\mathrm{H}(\mathrm{b})$

Additionally a differential analysis of the efficiency achieved for the prechamber $\mathrm{H} 1$ and $\mathrm{H} 2$ showed that:

- in the range of average excess air coefficient values, the values for both $\mathrm{H}$ type prechambers are similar,

- with small values of excess air coefficient and lower fuel doses to the prechamber, the $\mathrm{H} 1$ prechamber (smaller number of outflow channels) achieves higher efficiency,

- for the limit values of $\lambda>1.6$ greater efficiency is obtained using the $\mathrm{H} 2$ prechamber.

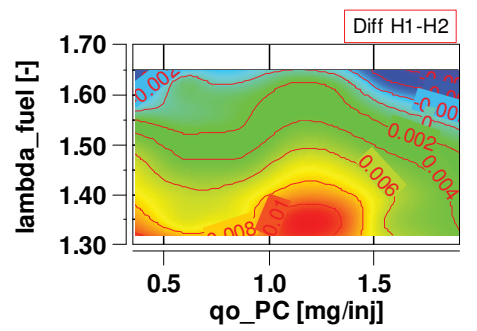

Fig. 15. The differential map of overall efficiency between prechambers of type $\mathrm{H}(\mathrm{H} 1-\mathrm{H} 2)$

\section{Emission measurement results evaluation}

The measured concentrations of toxic exhaust compounds are presented in the form of specific emission maps for comparison purposes. 
Figure 16 shows a map of nitrogen oxides emissions. The prechamber type $\mathrm{H}$ combustion system shows lower $\mathrm{NO}_{\mathrm{x}}$ emission over the whole emission map range compared to the type $\mathrm{P}$ prechamber. The most favorable result was obtained for the $\mathrm{H} 2$ prechamber, where there was the least discrepancy between the min and max values. The result depends mainly on global conditions (air excess coefficient $\lambda$ ) and a change in the trend is visible only for very small doses to the prechamber.

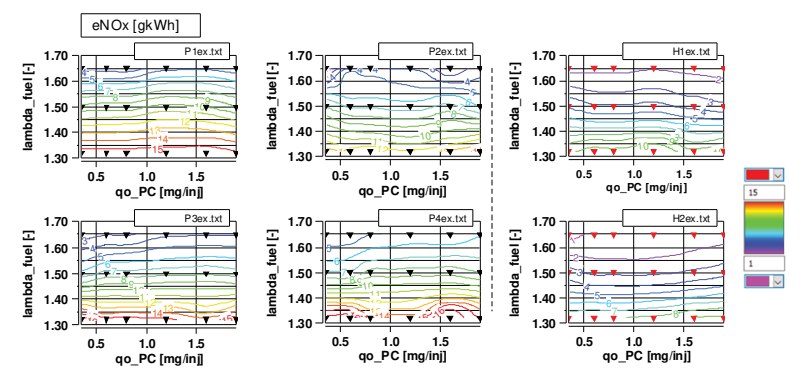

Fig. 16. The $\mathrm{NO}_{\mathrm{x}}$ emission maps obtained for prechamber type $\mathrm{P}$ (a) and type $\mathrm{H}(\mathrm{b})$

Hydrocarbon emission is shown in Fig. 17. As with $\mathrm{NO}_{\mathrm{x}}$, the best results were obtained for the H-prechamber, but the P3 and P4 prechambers have produced similar results, especially for the minimum doses of fuel for the PC. The global condition (lambda) has the most impact on the trend, but in relation to $\mathrm{NO}_{x}$, the effect of dosing to the PC can be observed (especially for P-type prechambers).

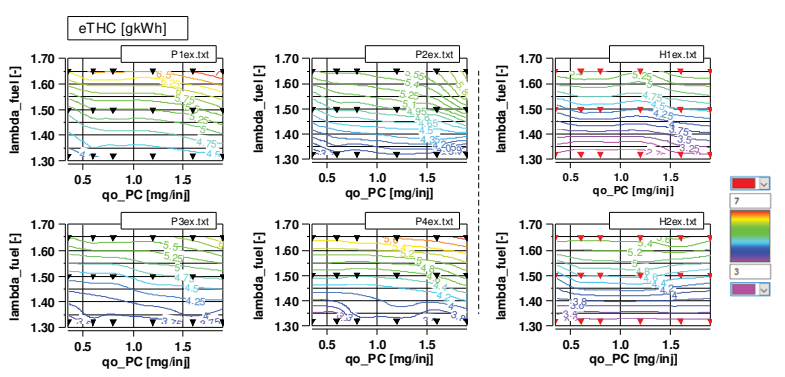

Fig. 17. The THC emission maps obtained for P- and H-type prechambers

As in the case of other emission factors, in the case of the carbon monoxide emission (Fig. 18) the H-type prechamber systems provided better emission results. In this case, however, the local conditions had more impact on the obtained values - such as the prechamber fuel dose. Global conditions affected the results distribution to a lesser degree. This tendency is opposite in relation to the other emission factors.
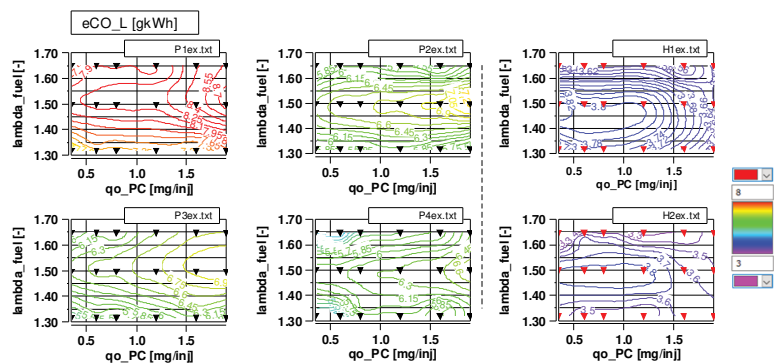

Fig. 18. The CO_L emission maps achieved for prechamber type $\mathrm{P}$ and type $\mathrm{H}$

\section{Polioptimization procedure}

\subsection{Methodology for determination of the best solution}

Due to the varied trends of changes in thermodynamic and emission factors, the polioptimization methodology involving three calculation variants was used:

- $1^{\text {st }}$ approach: modified selection of the ,best PC”:

- all prechambers have been taken into account,

- all $\lambda$-values were included in the procedure,

- values of fuel quantities and of $\lambda$ were normalized based on interpolation and extrapolation of the nearest values (for every indicator exist only one minand only one max-value),

$-2^{\text {nd }}$ approach: individualized selection of the „best PC”:

- all $\lambda$-values were included in the procedure,

- values of fuel quantities and of $\lambda$ were normalized based on interpolation and extrapolation of the nearest values (for every indicator exists only one min. and only one max-value) - as in the 1st approach,

- every PC was analyzed separately - for every PC the „best point” (1 out of 18) has been determined based on the values of $\mathrm{CO}, \mathrm{HC}, \mathrm{NO}_{\mathrm{x}}$, eta-o, IMEP, and CoV(IMEP),

- indication of advantages of individual engine operating points (1 out of 18) for every PC separately; such procedure makes it possible to define operating points with better engine indicators (could be usedfor setting the engine control unit),

- $3^{\text {rd }}$ approach: individualized and normalized selection of the „best PC":

- all values of $\lambda$ and fuel injection quantity have been normalized,

- every PC was analyzed separately - for every PC the „best point” (1 out of 18) was selected,

- advantages for every engine operating point (1 out of 18) have been selected for every PC separately,

- each lambdavalue was analyzed separately: for every PC and each lambda the "best PC" has been chosen.

\section{2. $1^{\text {st }}$ approach: modified selection of the „best PC"}

The optimization procedure was performed in the following manner:

- the emission results of $\mathrm{CO}, \mathrm{THC}, \mathrm{NO}_{\mathrm{x}}$ and for overall efficiency were interpolated or extrapolated respectively,

- the following methodology was adopted (for each prechamber):

- selection of the global (for all 9 cases) min and max values for every component,

- normalizing all absolute measured values to the relative values in the range $<0 ; 1>$ :

- max of emission - value 0

- min of emission - value 1

- max of efficiency - value 1

- $\min$ of efficiency - value 0

- determining the quantities totals for all 18 operating points,

- varying selection of the impact factors (IF) for every emission component and efficiency $(\Sigma=1)$; IMEPvalues were not taken into account $(\mathrm{IF}=0)$, 
- determining the products of sums and impact factors,

- the designation of the resulting sums.

Results of these analyzes have been summed up in Table 5 and Fig. 19.

Table 5. Selection of the best combustion system configuration for different impact factor values (1st approach): a) all 0.25 ; b) eta_o $=0.4, c)$ eta_o $=0.55$

a)

\begin{tabular}{|c|c|c|c|c|c|c|c|}
\hline Factor & Chamber & P1 & P2 & P3 & P4 & $\mathrm{H} 1$ & $\mathrm{H} 2$ \\
\hline 0.25 & eCO_L & $\nabla 2.47$ & $=7.93$ & $=7.47$ & $=8.83$ & $\triangle 15.04$ & $\triangle 15.73$ \\
\hline 0.25 & eta_o & $\nabla 2.72$ & - 7.83 & $\square 7.68$ & - 8.92 & $=10.87$ & 9.98 \\
\hline 0.25 & eTHC & $\nabla 6.58$ & $\square 8.69$ & $\square 9.64$ & $=9.93$ & $\triangle 11.40$ & $=10.64$ \\
\hline 0.25 & eNOx & $=7.66$ & - 9.91 & $\square 8.84$ & $=7.89$ & $\triangle 12.56$ & $\triangle 13.75$ \\
\hline 0 & IMEP_av & $\nabla 2.25$ & $\nabla 6.54$ & $\nabla 5.10$ & $\nabla 5.84$ & $=9.38$ & $=9.91$ \\
\hline 0 & CoV_IMEP & $\nabla 7.06$ & 9.34 & $\nabla 7.76$ & $=10.07$ & $\triangle 11.76$ & $\Delta 12.22$ \\
\hline & Best & $\nabla 4.86$ & -8.59 & $=8.41$ & - 8.89 & $\triangle 12.47$ & $\Delta 12.53$ \\
\hline
\end{tabular}

b)

\begin{tabular}{|c|c|c|c|c|c|c|c|c|}
\hline Factor & Chamber & P1 & P2 & P3 & & P4 & H1 & $\mathrm{H} 2$ \\
\hline 0.2 & eCO_L & $\nabla 2.47$ & $=7.93$ & $=7.47$ & $\overline{\nabla \varepsilon}$ & 8.83 & $\triangle 15.04$ & $\triangle 15.73$ \\
\hline 0.4 & eta_o & $\nabla 2.72$ & $\square 7.83$ & $\square 7.68$ & $\square \varepsilon$ & 8.92 & $=10.87$ & 9.98 \\
\hline 0.2 & етнс & $\nabla 6.58$ & $\square 8.69$ & — 9.64 & $\square s$ & 9.93 & $\triangle 11.40$ & $=10.64$ \\
\hline 0.2 & eNOx & $=7.66$ & - 9.91 & - 8.84 & $=7$ & 7.89 & $\triangle 12.56$ & $\triangle 13.75$ \\
\hline 0 & IMEP_av & $\nabla 2.25$ & $\nabla 6.54$ & $\nabla 5.10$ & $\nabla 5$ & 5.84 & 9.38 & - 9.91 \\
\hline \multirow[t]{2}{*}{0} & CoV_IMEP & $\nabla 7.06$ & 9.34 & $\nabla 7.76$ & $\square 1$ & 10.07 & $\Delta 11.76$ & $\Delta 12.22$ \\
\hline & Best & $\nabla 4.43$ & - 8.44 & $=8.26$ & & 8.90 & $\Delta 12.15$ & $\triangle 12.02$ \\
\hline
\end{tabular}

c)

\begin{tabular}{|c|c|c|c|c|c|c|c|}
\hline Factor & Chamber & P1 & P2 & P3 & P4 & $\mathrm{H} 1$ & $\mathrm{H} 2$ \\
\hline 0.15 & eCO_L & $\nabla 2.47$ & $=7.93$ & $=7.47$ & -8.83 & $\triangle 15.04$ & $\triangle 15.73$ \\
\hline 0.55 & eta_o & $\nabla 2.72$ & - 7.83 & $=7.68$ & — 8.92 & —10.87 & 9.98 \\
\hline 0.15 & етнс & $\nabla 6.58$ & $\square 8.69$ & $\square 9.64$ & $\square .93$ & $\triangle 11.40$ & $=10.64$ \\
\hline 0.15 & eNOx & 7.66 & $\square 9.91$ & $\square 8.84$ & $\square 7.89$ & $\triangle 12.56$ & $\triangle 13.75$ \\
\hline 0 & IMEP_av & $\nabla 2.25$ & $\nabla 6.54$ & $\nabla 5.10$ & $\nabla 5.84$ & $=9.38$ & $=9.91$ \\
\hline 0 & COV_IMEP & $\nabla 7.06$ & - 9.34 & $\nabla 7.76$ & 10.07 & $\triangle 11.76$ & $\therefore 12.22$ \\
\hline
\end{tabular}

\begin{tabular}{llccc} 
& Place: & $\mathbf{1}$ & $\mathbf{2}$ & $\mathbf{3}$ \\
\cline { 3 - 5 } $\begin{array}{l}\text { Impact factors } \\
\text { equal }\end{array}$ & Best chamber & H2 & H1 & P4 \\
\hline $\begin{array}{l}\text { Higher factor } \\
\text { for efficiency } \\
\text { (0.4) }\end{array}$ & Best chamber & H1 & H2 & P4 \\
\hline $\begin{array}{l}\text { The highest } \\
\text { factor for } \\
\text { efficiency } \\
\text { (0.55) }\end{array}$ & Best chamber & H1 & H2 & P4 \\
\hline
\end{tabular}

Fig. 19. Results of the search for the best configuration of the combustion system for different impact factors assigned to different coefficients ( $1^{\text {st }}$ approach)

\section{4. $2^{\text {nd }}$ approach: individualized selection of the ,best} PC"

In this case the following procedure has been performed:

- all lambda values were included in the procedure;

- values of fuel quantities and of lambda were normalized based on interpolation and extrapolation of the nearest values (for every indicator exists only one min and only one max-value) - as in the $1^{\text {st }}$ approach,

- every PC was analyzed separately - for every PC the „best point" (1 out of 18) according values of $\mathrm{CO}, \mathrm{HC}$, $\mathrm{NO}_{\mathrm{x}}$, eta_o, IMEP has been selected,

indication of advantages of individual engine operating points (1 out of 18) for every PC separately; such procedure makes it possible to define points with more favorable engine indicators (could be used for setting the engine control unit).
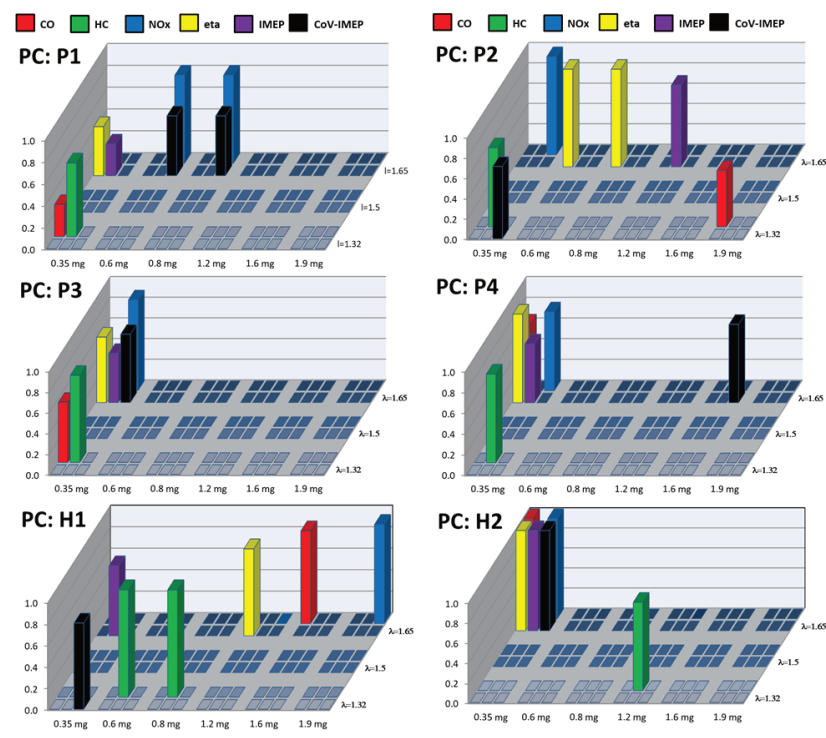

Fig. 20. Selection of the best combustion system configuration for different impact factors assigned to different coefficients ( $2^{\text {nd }}$ approach)

Conclusions from the $2^{\text {nd }}$ approach were following:

- „Lowest emissions” for min. of qo_PC,

- „Highest efficiency” for min. of qo_PC,

- „Best points”: 6 (min. qo_PC $\& \lambda=1.65$ ),

- PC P4: all engine indicators for min. of qo_PC,

- PC H2: best emission indicators.

8.5. $3^{\text {rd }}$ approach: individualized and normalized selection of the ,best PC"

Methodology described in chapter 8.4 was modified as follows:

- all values of lambda and fuel injection quantity have been normalized,

- every PC was analyzed separately - for every PC the „best point” (1 out of 18) was selected,

- advantages for every engine operating point (1 out of 18) have been selected for every PC separately,

- each lambda value was analyzed separately: for every PC and for each lambda the ,best PC” has been chosen.

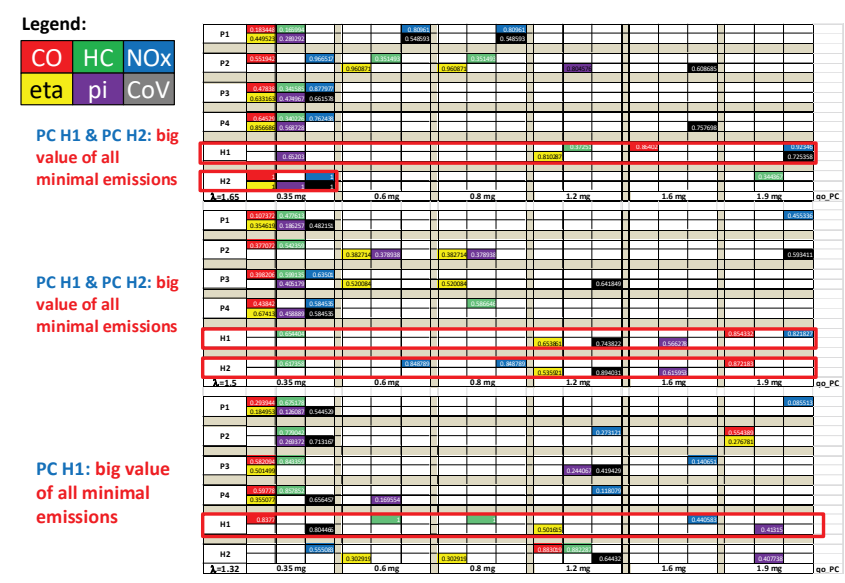

Fig. 21. Selection of the best combustion system configuration for different impact factors assigned to different coefficients ( $3^{\text {rd }}$ approach)

Following conclusions were reached from the $3^{\text {rd }}$ approach: 
- Best prechamber: $\mathrm{PC} \mathrm{H} 2$

- Lambda $=1.65$

- the best indicators for higher lambda values,

- all indicators found for one operating point;

- Lambda $=1.5$

- many maximum indicator values at one engine operating point,

- only the maximum efficiency found for the operating point close to selected one,

- $\quad$ Lambda $=1.3$

- min. $\mathrm{CO}$ and min. $\mathrm{HC}$ emission for the same operating point as above (qo_PC $\rightarrow$ min)

- high efficiency for this point.

\section{Summary and conclusions}

The polioptimization method has been applied to the selective research on the prechambers construction. The aim of the study was to create a comparison procedure for prechamber systems having multiple variable parameters based on the characteristic measurement points and providing the configuration assessment result based on the selected criteria (emissions, efficiency or combustion stability) and highlighting the operating points that score high on these criteria. Two combustion system configurations have been tested:

- $\omega$-type piston cavity with PFI and 4 prechamberswithout bottom orientated nozzles,

- hemispherical piston cavity with Heinzmann-mixer, two prechambers with nozzles orientated radially and axially.

Three different selection procedures have been analyzed and compared:

- $1^{\text {st }}$ modified approach,

$-2^{\text {nd }}$ individualized approach,

- $3^{\text {rd }}$ individualized and normalized approach.

In all investigated cases the 18 real operating points (variable $\lambda$ and $\mathrm{q}_{0 \_\mathrm{PC}}$ ) have been normalized using the interpolation and extrapolation procedures, therefore ensuring their comparability.

Based on the measured emissions $\left(\mathrm{CO}, \mathrm{THC}, \mathrm{NO}_{\mathrm{x}}\right)$ and efficiency, the approach-dependent matrix of beneficial configurations has been drawn (Table 6).

Independently from the approach described (Table 4), better results were achieved for the combustion system in its second configuration - with hemispherical main chamber, Heinzmann-mixer fuel supply system and prechambers providing the axial development of igniting jets - to the chamber's bottom. This is the result of the better main mixture homogenization and better distribution of igniting jets in the main combustion chamber volume.

Table 6. Approach-dependent matrix of best PC configurations

\begin{tabular}{|l|l|}
\hline $\begin{array}{l}1^{\text {st }} \text { approach } \\
\text { (extrapolated data } \\
\text { - one „best” PC) }\end{array}$ & Best: PC H2 (overall) \& PC H1 (efficiency) \\
\hline $\begin{array}{l}2^{\text {st }} \text { approach } \\
\text { (individual „best” PC } \\
\text { - all researach point) }\end{array}$ & Best: PC H2 (overall) \& PC H1 (emission) \\
\hline $\begin{array}{l}3^{\text {st approach }} \text { (individual „best” PC \& } \\
\text { for each lambda value) }\end{array}$ & Best: PC H1 (best for all lambda-value) \\
\hline
\end{tabular}

Using the first approach, and assuming similar importance of emissions and efficiency, prechamber $\mathrm{H} 2$ indicated the best results. When considering the engine overall efficiency as more important, the prechamber $\mathrm{H} 1$ achieved better results. This PC had a greater nozzle flow area, which leads to a smaller velocity of igniting jet, therefore smaller jet-wall effect (reducing the heat flux to the piston) and better distribution of the jets in the direction perpendicular to the flow. Both contribute to better overall engine efficiency.

Second approach indicates the best operating points individually for each prechamber and separately for each criteria. When taking into account all assessment criteria combined - emissions, efficiency, achieved IMEP and combustion stability- the best results distribution has been achieved for the prechamber $\mathrm{H} 2$ (second combustion system configuration). However, with focus on emissions, more beneficial operating points have been found for prechamber H1.

Based on the results from the third approach, it is stated, that measurements done with prechamber $\mathrm{H} 1$ resulted in the biggest spread of minimal values (in combination with their beneficial values) over the investigated range of $\lambda$ and $\mathrm{q}_{0} \mathrm{PC}$.

The investigation results from all proposed approaches suggest that the total best results have been achieved for the second configuration of combustion system with prechamber $\mathrm{H} 1$.

\section{Acknowledgements}

This work was supported by the EU - Horizon 2020 [grant number 652816].

\section{Nomenclature}

\author{
A area \\ AI heat release angle $(10 \%-$ SOC or $90 \%-$ EOC) \\ $\mathrm{CoV}$ coefficient of variation \\ CR compression ratio \\ qo fuel dose \\ CI compression ignition \\ $\mathrm{CNG}$ compressed natural gas \\ CoC centre of combustion (AI50) \\ CO_L carbon monoxide (low value) \\ EOC end of combustion
}

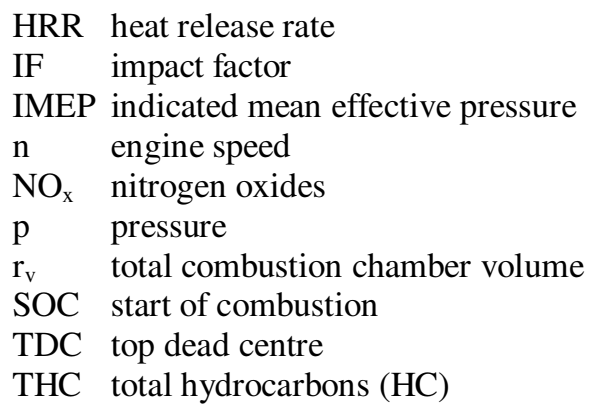




$\begin{array}{llll}\text { TJI } & \text { turbulent jet ignition } & \lambda & \text { lambda value } \\ \text { V } & \text { volume } & \eta & \text { efficiency } \\ \text { WOT } & \text { wide open throttle } & \emptyset & \text { diameter }\end{array}$

\section{Indexes}

$\begin{array}{llll}\text { air } & \text { air } & \mathrm{o} & \text { overall } \\ \text { ch } & \text { chamber } & \mathrm{PC} & \text { prechamber } \\ \text { exh } & \text { exhaust } & \mathrm{t} & \text { thermal } \\ \mathrm{MC} & \text { main chamber } & \mathrm{V} & \text { volume }\end{array}$

\section{Bibliography}

[1] ATTARD, W.P., BLAXILL, H., ANDERSON, E., LITKE, P., Knock limit extension with a gasoline fueled prechamber jet igniter in a modern vehicle powertrain. $S A E$ Technical Paper 2012-01-1143. 2012. DOI:10.4271/201201-1143.

[2] ATTARD, W.P., FRASER, N., PARSONS, P., TOULSON, E. A turbulent jet ignition pre-chamber combustion system for large fuel economy improvements in a modern vehicle powertrain. SAE Technical Paper 2010-01-1457. 2010. DOI: $10.4271 / 2010-01-1457$.

[3] ATTARD, W.P., PARSONS, P. A normally aspirated spark initiated combustion system capable of high load, high efficiency and near zero $\mathrm{NO}_{\mathrm{x}}$ emissions in a modern vehicle powertrain. SAE International Journal of Engines. 2010, 3(2), 269-287.

[4] BUNCE, M., BLAXILL, H., KULATILAKA, W., JIANG, $N$. The effects of turbulent jet characteristics on engine performance using a pre-chamber combustor. SAE Technical Paper 2014-01-1195. 2014. DOI:10.4271/2014-01-1195.

[5] FARZANEH-GORDA, M., SAADAT-TARGHI, M., KHADEM, J. Selecting optimal volume ratio of reservoir tanks in CNG refueling station with multi-line storage system. International Journal of Hydrogen Energy. 2016, 41 (48), 23109-23119, DOI:10.1016/j.jihydene.2016.10.050.

[6] FERRERA, M. Highly efficient natural gas engines. SAE Technical Paper 2017-24-0059, 2017, DOI:10.4271/201724-0059.

[7] GEOK, H., MOHAMAD, T., ABDULLAH, S., et al. Experimental investigation of performance and emissions of a sequential port injection compressed natural gas converted engine. SAE Technical Paper 2009-32-0026. 2009.

[8] Global energy statistical yearbook 2018. https://yearbook. enerdata.net/oil-products/world-refined-productionstatistics.html (accessed 20.12.2018).

[9] JAMROZIK, A., TUTAK, W., KOCISZEWSKI, A., SOSNOWSKI, M. Numerical simulation of two-stage combustion in SI engine with prechamber. Applied Mathematical Modelling. 2013, 37, 2961-2982.

[10] KAGIRI, C., ZHANG, L., XIA, X. Optimal energy cost management of a CNG fuelling station. IFAC Papers-OnLine. 2017, 50-2, 94-97. DOI:10.1016/j.ifacol.2017.12.017.

[11] KHAN, M.I., YASMEEN, T., M.I. KHAN, M. et al. Research progress in the development of natural gas as fuel for road vehicles: A bibliographic review (1991-2016). Renewable and Sustainable Energy Reviews. 2016, 66, 702-741, DOI: 10.1016/j.rser.2016.08.041.

[12] KOTZAGIANNI, M., KYRTATOS, P., BOUlOUCHOS, $\mathrm{K}$., Optical investigation of prechamber combustion in RCEM. Combustion Engines. 2019, 176(1), 12-17. DOI: 10.19206/CE-2019-102.

[13] NAKAZANO, T., NATSUME, Y. Effect of dimensions of prechamber on lean burn gas engine. Japan Society of Me- chanical Engineers International Journal. 1994, 37-B(4), 951-956.

[14] OLSEN, D.B., KIRKPATRICK, A. Experimental examination of prechamber heat release in a large bore natural gas engine. Journal of Engineering for Gas Turbines and Power. 2008, 130(5). DOI:10.1115/1.2906182.

[15] PIELECHA, I., BUESCHKE, W., CIEŚLIK, W., SKOWRON, M. Turbulent spark-jet ignition in SI gas fuelled engine. MATEC Web of Conferences. 2017, 118, 00010. DOI: 10.1051/matecconf/201711800010.

[16] PIELECHA, I., WISŁOCKI, K., BUESCHKE, W. et al. Influence of gas injector position on the engine performance of a dual-fuel diesel engine. FISITA World Automotive Congress. 2016.

[17] PIRKER, G., WIMMER, A. Sustainable power generation with large gas engines. Energy Conversion and Management. 2017, 149, 1048-1065. DOI:10.1016/ j.enconman. 2017.06.023.

[18] PIZZUTI, L., MARTINS, A.M., dos SANTOS, L.R. et al. Laminar burning velocity of methane/ air mixtures and flame propagation speed close to the chamber wall. Energy Procedia. 2017, 120, 126-133. DOI:10.1016/j.egypro. 2017.07.145.

[19] ROULEAU, L., SERRANO, D., LECOINTE, B. CNG direct injection spark-ignition engine with high turbulence and high compression ratio: numerical and experimental investigations. 12th Conference Gaseous-Fuel Powered Vehicles A Sustainable Alternative. Stuttgart 2017.

[20] SHAH, A., TUNESTAL, P., JOHANSSON, B. Effect of prechamber volume and nozzle diameter on pre-chamber ignition in heavy duty natural gas engines. SAE Technical Paper 2015-01-0867. 2015. DOI:10.4271/2015-01-0867.

[21] SHAH, A., TUNESTAL, P., JOHANSSON, B. Scalability aspects on pre-chamber ignition in heavy duty natural gas engines. SAE Technical Paper 2016-01-0796. 2016. DOI: 10.4271/2016-01-0796.

[22] SOLTIC, P., HILFIKER, T., HÄNGGI, S. et al. Ignitionand combustion concepts for lean operated passenger car natural gas engines. 12th Conference Gaseous-Fuel Powered Vehicles a Sustainable Alternative. Stuttgart 2017.

[23] SOlTIC, P., HILFIKER, T., HUTTER, R., HÄNGGI, S. Experimental comparison of efficiency and emission levels of four-cylinder lean-burn passenger car-sized CNG engines with different ignition concepts. Combustion Engines. 2019, 176(1), 29-37. DOI:10.19206/CE-2019-104.

[24] ŚLEFARSKI, R., GOŁĘBIOWSKI, M., CZYŻEWSKI, P. et al. Analysis of combustion process in industrial gas engine with prechamber-based ignition system. Energies. 2018, 336(11). DOI:10.3390/en11020336.

[25] TOULSON, E., SCHOCK, H.J., ATTARD, W.P. A review of pre-chamber initiated jet ignition combustion systems. SAE Technical Paper 2010-01-2263. 2010. DOI: 10.4271/ 2010-01-2263. 
[26] U.S. Energy Information Administration, International Energy Outlook 2016, Chapter 8, 127-131. https://www.eia.gov/outlooks/ieo/pdf/transportation.pdf.

[27] VALLE, R.M., CANDIDO de SA, D.C., RAMALHO FILHO, F.A. Constructive parameters analysis of combustion pre-chamber adopted in torch-ignition system of Otto cycle engine. SAE Technical Paper 2003-01-3713. 2003. DOI: 10.4271/2003-01-3713.

[28] Worldwide car production through 2017. www.statista.com (accessed 10.12.2018).

Prof. Ireneusz Pielecha, DSc., DEng. - Faculty of Transport Engineering, Poznan University of Technology.

e-mail: Ireneusz.Pielecha@put.poznan.pl

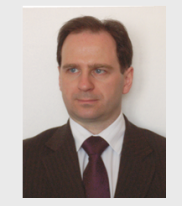

Maciej Skowron, MEng. - Faculty of Transport Engineering, Poznan University of Technology.

e-mail: Maciej.Skowron@put.poznan.pl

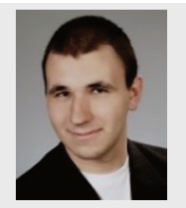

Filip Szwajca, MEng. - Faculty of Transport Engineering, Poznan University of Technology.

e-mail: Filip.Szwajca@put.poznan.pl

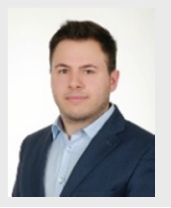

Prof. Krzysztof Wisłocki, DSc., DEng. - Faculty of Transport Engineering, Poznan University of Technology.

e-mail: Krzysztof.Wislocki@put.poznan.pl
[29] YANG, C., LI, W., YIN, J., SHEN, Y. Port fuel injection of CNG for downsized 1-liter 3-cylinder turbocharged engine with high efficiency. SAE Technical Paper 2017-01-2275. 2017. DOI:10.4271/2017-01-2275.

[30] ZHENG, J.-J., WANG, J.-H., WANG, B., HUANG, Z.-H. Effect of the compression ratio on the performance and combustion of a natural-gas direct-injection engine. Proceedings of the Institution of Mechanical Engineers, Part D: Journal of Automobile Engineering. 2009, 223(1), 85-98. DOI:10.1243/09544070JAUTO976.

Wojciech Bueschke, DEng. - Faculty of Transport Engineering, Poznan University of Technology. e-mail:Wojciech.Bueschke@put.poznan.pl

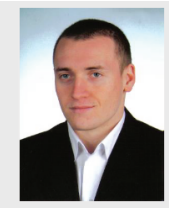

Łukasz Fiedkiewicz, MEng. - Faculty of Transport Engineering, Poznan University of Technology.

e-mail: Lukasz.Fiedkiewicz@put.poznan.pl

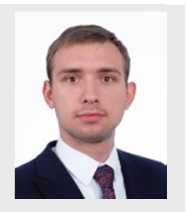

Wojciech Cieślik, DEng. - Faculty of Transport

Engineering, Poznan University of Technology.

e-mail: Wojciech.Cieslik@put.poznan.pl 